\title{
Biodegradation of Polyethylene by Enterobacter sp. D1 from the Guts of Wax Moth Galleria mellonella
}

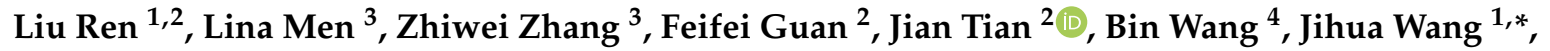 \\ Yuhong Zhang ${ }^{2, *}$ (iD and Wei Zhang ${ }^{2}$ \\ 1 College of Life Science and Technology, Harbin Normal University, No. 1 Shida Road., Limin Economic \\ Development Zone, Harbin 150025, China; rllr1@outlook.com \\ 2 Biotechnology Research Institute, Chinese Academy of Agricultural Sciences, No. 12 Zhongguancun South \\ Street., Beijing 100081, China; guanfeifei@caas.cn (F.G.); tianjian@caas.cn (J.T.); zhangwei02@caas.cn (W.Z.) \\ 3 College of Forestry, Shanxi Agricultural University, Taigu 030801, China; linamen81@163.com (L.M.); \\ zhiweizhang2012@163.com (Z.Z.) \\ 4 Institute of Soil Fertilizer and Agricultural Water Saving, Xinjiang Academy of Agricultural Sciences, \\ Urumqi 830091, China; wbx_wm@126.com \\ * Correspondence: wangjihua333@hotmail.com (J.W.); zhangyuhong@caas.cn (Y.Z.)
}

Received: 28 April 2019; Accepted: 29 May 2019; Published: 31 May 2019

\begin{abstract}
Plastic polymers are widely used in agriculture, industry, and our daily life because of their convenient and economic properties. However, pollution caused by plastic polymers, especially polyethylene (PE), affects both animal and human health when they aggregate in the environment, as they are not easily degraded under natural conditions. In this study, Enterobacter sp. D1 was isolated from the guts of wax moth (Galleria mellonella). Microbial colonies formed around a PE film after 14 days of cultivation with D1. Roughness, depressions, and cracks were detected on the surface of the PE film by scanning electron microscopy (SEM) and atomic force microscopy (AFM). Fourier transform infrared spectroscopy (FTIR) showed the presence of carbonyl functional groups and ether groups on the PE film that was treated with D1. Liquid chromatography-tandem mass spectrometry (LC-MS) also revealed that the contents of certain alcohols, esters, and acids were increased as a result of the D1 treatment, indicating that oxidation reaction occurred on the surface of the PE film treated with D1 bacteria. These observations confirmed that D1 bacteria has an ability to degrade PE.
\end{abstract}

Keywords: environmental impact; Enterobacter sp.; plastic biodegradation; polyethylene; wax moth

\section{Introduction}

Plastic polymers have advantages of ductility, durability, and low cost, and are commonly used in agricultural films and food packaging. However, plastic pollution poses a serious threat to animal and human health. Mircroplastics are of particular concern, as microplastics are deposited in aquatic environments, and microplastics ingested by seabirds or fish accumulate in their stomachs, which may cause death [1,2]. Furthermore, the potential accumulation of microplastics in the food chain eventually could have adverse effects on human health [3-5].

Incineration, landfilling, and recycling of plastic waste are costly and may cause secondary pollution $[1,6]$. The development of biodegradable plastics in recent years could slow down the accumulation of plastics in the environment, but fails to completely eliminate environmental pollution at the source $[7,8]$. Biodegradation, an eco-friendly method of degradation, is the process by which organic materials are decomposed or broken down into smaller compounds, including $\mathrm{CO}_{2}$ and $\mathrm{H}_{2} \mathrm{O}$, by microbial action. The process of biodegradation can be divided into four stages: (a) cells grow firmly on the surface of the plastic material and produce hydrophilic groups; (b) long-chain hydrocarbons are 
oxidized or hydrolyzed into short chains by enzymes produced by microbial population, and a new aggregated bond is formed; (c) short-chain polymers are further broken down into fatty acids; (d) fatty acids are oxidized and decomposed into $\mathrm{H}_{2} \mathrm{O}, \mathrm{CO}_{2}$, and humus $[9,10]$.

There are increasing research interests in the biodegradation of plastic polymers. Polyethylene (PE), the most widely used plastic polymer, is a synthetic polymer of high molecular weight containing a structure of linear saturated hydrocarbon, which can be expressed as $-\left[\mathrm{CH}_{2}-\mathrm{CH}_{2}\right]_{\mathrm{n}}-[11]$. The demand for $\mathrm{PE}$ accounted for about $30 \%$ of total plastic polymers in 2017, and the annual global production of PE is approximately 140 million tons [12,13]. Since the early 1970s, researchers have investigated the biodegradation of PE and found certain PE-degrading strains, including Bacillus, Pseudomonas, Staphylococcus, Streptococcus, Streptomyces, Brevibacterium, Nocardia, Moraxella, Penicillium, and Aspergillus from soil, marine, and sludge under natural conditions [1,13-15]. However, the strong hydrophobicity, high chemical bond energy, and high molecular weight of PE hinder its efficient degradation by most strains, especially within a short period of time [16]. It has been shown that the degradation of PE by fungus Penicillium simplicissimum and Nocardia asteroides could take several months or even longer [17]. Recently, Yang Jun et al. reported that PE could be significantly degraded by microorganisms of the Indian meal moths, and two strains, Enterobacter asburiae YT1 and Bacillus sp. YP1, were isolated. Following a 60 -day incubation, approximately $6 \%$ and $11 \%$ of a PE film was degraded by YT1 and YP1, respectively [11]. These results indicate that insects could be a promising source to obtain PE-degrading microorganisms. Similarly, Paolo Bombelli et al. found that there was $92 \mathrm{mg}$ mass loss of a PE shopping bag after exposure to $\sim 100$ wax worms, and ethylene glycol was produced for 12 hours [18]. Nonetheless, further studies are still needed to identify specific microorganisms that play a key role in the degradation of PE. Therefore, the aim of this study was to screen PE-degrading microorganisms from the guts of wax moth (Galleria mellonella), and the degradation efficiency and mechanisms were further determined using scanning electron microscopy (SEM) coupled to an energy dispersive spectroscopy (EDS), atomic force microscopy (AFM), Fourier transform infrared spectroscopy (FTIR), and liquid chromatography-tandem mass spectrometry (LC-MS).

\section{Materials and Methods}

\subsection{PE Film and Wax Moth Larvae}

PE film was purchased from the SINOPEC Beijing Yanshan Company in Beijing, China. The PE film was cut into a $40 \mathrm{~mm} \times 40 \mathrm{~mm}$ square, disinfected with $75 \%$ ethanol and air-dried, and then used as the sole carbon source for the growth of microorganisms in a shake flask or on a plate.

The wax moth larvae were collected from natural bee farms in Beijing and raised at Shanxi Agricultural University (with beeswax as the main food). The beeswax, as a source of food for the wax moth, is a 'natural plastic' with a chemical structure similar to that of PE. Hence, the wax moth can be used to screen the microorganisms that "feed" PE plastic.

\subsection{Medium}

The liquid basal medium in which PE was the sole carbon source (LPEM) contained (per $1000 \mathrm{~mL}$ ): $0.7 \mathrm{~g}$ of $\mathrm{KH}_{2} \mathrm{PO}_{4}, 0.7 \mathrm{~g}$ of $\mathrm{K}_{2} \mathrm{HPO}_{4}, 0.7 \mathrm{~g}$ of $\mathrm{MgSO}_{4} \cdot 7 \mathrm{H}_{2} \mathrm{O}, 1.0 \mathrm{~g}$ of $\mathrm{NH}_{4} \mathrm{NO}_{3}, 0.005 \mathrm{~g}$ of NaCl, $0.002 \mathrm{~g}$ of $\mathrm{FeSO}_{4} \cdot 7 \mathrm{H}_{2} \mathrm{O}, 0.002 \mathrm{~g}$ of $\mathrm{ZnSO}_{4} \cdot 7 \mathrm{H}_{2} \mathrm{O}$, and $0.001 \mathrm{~g}$ of $\mathrm{MnSO}_{4} \cdot \mathrm{H}_{2} \mathrm{O}$, according to the ASTM standard (ASTM G22-76) [19]. A carbon-free source agar solid medium (APEM) was prepared by adding $15 \mathrm{~g}$ agar to $1000 \mathrm{~mL}$ of liquid basal medium. The liquid nutrient broth (LNB) medium was prepared by dissolving $3 \mathrm{~g}$ of beef extract, $10 \mathrm{~g}$ of bacteriological tryptone, and $5 \mathrm{~g}$ of $\mathrm{NaCl}$ in $1000 \mathrm{~mL}$ of deionized water and then the $\mathrm{pH}$ was adjusted to approximately 7.0. The solid nutrient broth (SNB) was prepared by adding $15 \mathrm{~g}$ of agar to $1000 \mathrm{~mL}$ of LNB. Physiological saline was prepared by dissolving $8.5 \mathrm{~g}$ of $\mathrm{NaCl}$ in $1000 \mathrm{~mL}$ of deionized water, and then the $\mathrm{pH}$ was adjusted to about 7.0. All media were autoclaved at $121^{\circ} \mathrm{C}$ for $20 \mathrm{~min}$. 


\subsection{Microbial Sample}

Wax moth larvae were immersed in $75 \%$ ethanol for about 1 min for disinfection, and then the larvae's guts were dissected and placed in a 50-mL centrifuge tube and washed with sterile physiological saline three times. Then, $40 \mathrm{~mL}$ of sterile physiological saline was added followed by vortexing to obtain an intestinal homogenate. The intestinal homogenate was used to screen PE-degrading microorganisms.

\subsection{Screening of PE-Degrading Strains}

The intestinal homogenate was inoculated into the LPEM (containing 1\% PE) and cultured at $37^{\circ} \mathrm{C}(220 \mathrm{r} / \mathrm{min})$. After 31 days, the bacterial solution was coated on the SNB medium and cultured for $12 \mathrm{~h}$. The colonies grown on the plate were considered as primary screening colonies for PE-degrading bacteria.

\subsection{The Biodegradation Test and Identification of PE-Degrading Strains}

The primary screening colonies were inoculated into the LNB for $12 \mathrm{~h}$. The cells were collected by centrifugation at $12,000 \mathrm{r} / \mathrm{min}$ and rinsed with sterile physiological saline, which was repeated three times to remove residual medium. Then, the cells were re-suspended with sterile physiological saline. The obtained suspension was inoculated into the LPEM, and a 5\% PE sheet $(40 \mathrm{~mm} \times 40 \mathrm{~mm})$ was added. Simultaneously, $500 \mathrm{uL}$ of suspension was coated on the APEM and covered with the PE sheet ( $40 \mathrm{~mm} \times 40 \mathrm{~mm}$ ). A blank control, without inoculation of bacterial liquid, was also tested. There were three replicates for each sample. All the shake flasks and solid medium were kept at $37^{\circ} \mathrm{C}(220 \mathrm{r} / \mathrm{min})$ for 31 days. The optical density at $600 \mathrm{~nm}\left(O D_{600}\right)$ of the shake flask was monitored regularly during the period of cultivation.

The genomic DNA was extracted from the bacterial solution by proteinase $\mathrm{K}$ treatment and phenol-chloroform. The $16 \mathrm{~S}$ rDNA sequence was amplified using universal primers $27 \mathrm{~F}$ (5' - AGAGTTTGATCMTGGCTCAG-3') and 1492R (5' - GGTTACCTTGTTACGACTT- $\left.3^{\prime}\right)$. The obtained sequences were submitted to the National Centre for Biotechnology Information (NCBI) GenBank database and aligned using the search tool Basic Local Alignment Search Tool (BLAST, http://www.ncbi.nlm.nih.gov/BLAST/).

\subsection{Observation of SEM and AFM}

The PE film was recovered from the shake flask after the cultivation, and then placed in the centrifuge tube containing sterile water and shaken on a vortex mixer according to the methods of Yang Jun et al. [11]. The dried PE film was cut into 5-mm sized pieces and coated with gold. The surface topography, biofilm, and atom contents of the microbe-treated or untreated PE were observed under SEM (Carl Zeiss NTS GmbH, Jena, Germany) coupled with EDS (Oxford Instruments, Abingdon, Oxfordshire, UK). The recovered PE film was washed with $2 \% \mathrm{w} / \mathrm{v}$ aqueous sodium dodecyl sulfate (SDS) to thoroughly remove the biofilm adhered to the PE surface and dried overnight [20]. The surface topography was observed by AFM (Dimension Icon, Veeco, Billerica, MA, USA) at a scan speed of $1.0 \mathrm{~Hz}$.

\subsection{Analysis of Spectroscopy}

The characterization of functional groups of the PE film surface was determined by FTIR (Nicolet iN10MX, Nicolet, Madison, WI, USA). The view field of the FTIR microscope was $400 \mu \mathrm{m} \times 400 \mu \mathrm{m}$, and the scanning was performed at a step size of $10 \mu \mathrm{m}$ under a contact pressure of $3 \mathrm{MPa}$. The absorbance ranged from $4000 \mathrm{~cm}^{-1}$ to $650 \mathrm{~cm}^{-1}$ with a scan resolution of $4 \mathrm{~cm}^{-1}$ for the FTIR. A background scan was performed each time before the sample was scanned, and the final sample spectrum was subtracted from the background scan value. 


\subsection{Detection of Water-Soluble Products}

The 31-day culture solution from the shake flask was centrifuged at 12,000 r/min for $10 \mathrm{~min}$ to obtain the supernatant. The $30 \mathrm{~mL}$ supernatant was freeze-dried and then re-dissolved in $1 \mathrm{~mL}$ of $50 \%$ ethanol, and centrifuged again at 12,000 r/min for $10 \mathrm{~min}$ after performing ultrasound for $10 \mathrm{~min}$. Then, $2 \mu \mathrm{L}$ of supernatant was used for LC-MS (AB Sciex TripleTOF ${ }^{\circledR} 5600+$, AB SCIEX, Redwood, CA, USA) analysis. The degradation products were detected by LC-MS equipped with a Waters ${ }^{\mathrm{TM}}$ HSS T3 $(150 \times 3 \mathrm{~mm}, 1.8 \mu \mathrm{m}$, Waters, Milford, MA, USA) at 100-1500 m/z. The column temperature was $35^{\circ} \mathrm{C}$ and the flow rate was $0.300 \mathrm{~mL} / \mathrm{min}$ during operation.

\subsection{Statistical Analyses}

All experiments were done in triplicate, and standard deviations have been presented as the error bars in Figures 1a and 2a. The mean variables and standard deviation were analyzed by Statistical Program for Social Sciences (SPSS 20.0, Chicago, IL, USA).

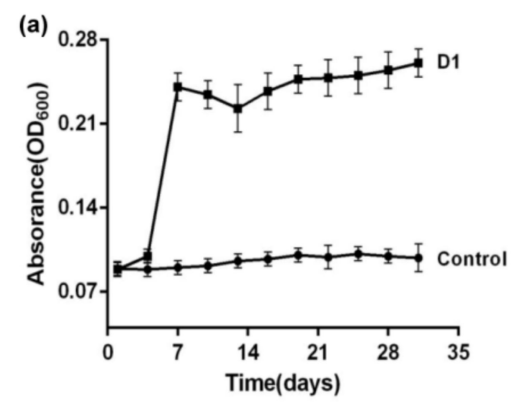

(b)

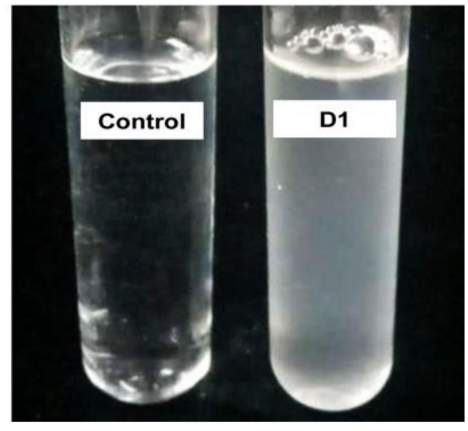

(c)

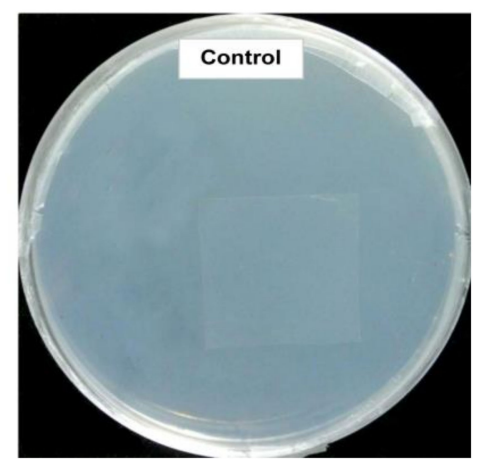

(d)

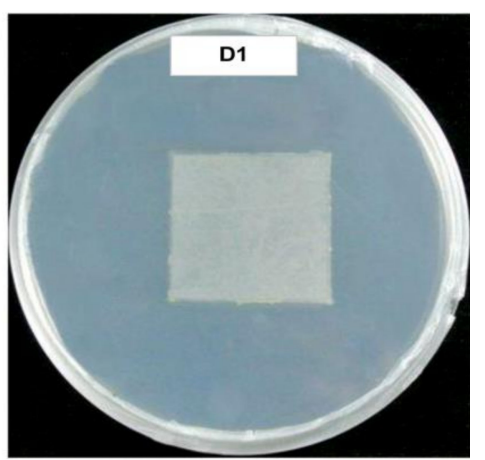

Figure 1. The growth of bacteria D1 in the medium in which a polyethylene (PE) film was the only carbon source. (a) The changes of optical density at $600 \mathrm{~nm}\left(O D_{600}\right)$ during the 31-day cultivation. (b) Turbidity of the D1 bacteria solution. (c) Plate of control group containing PE film without D1. (d) D1 colonies grown around the PE film on the carbon-free source agar solid medium (APEM).
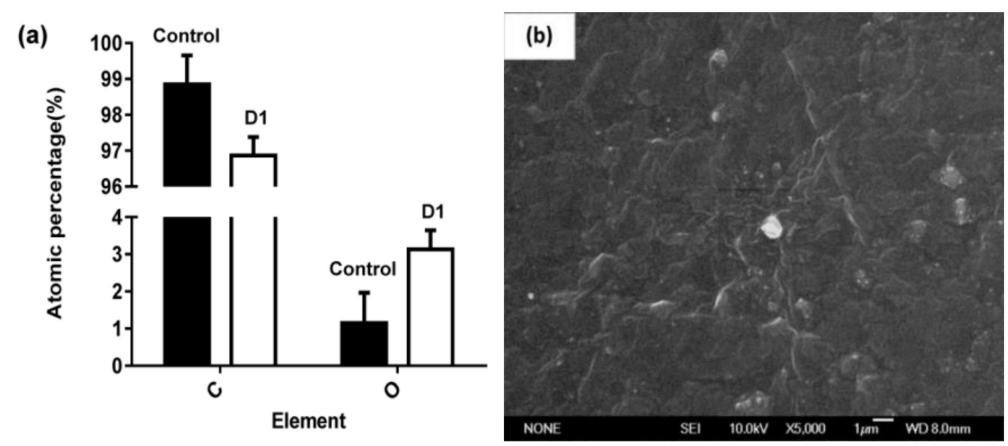

Figure 2. Cont. 

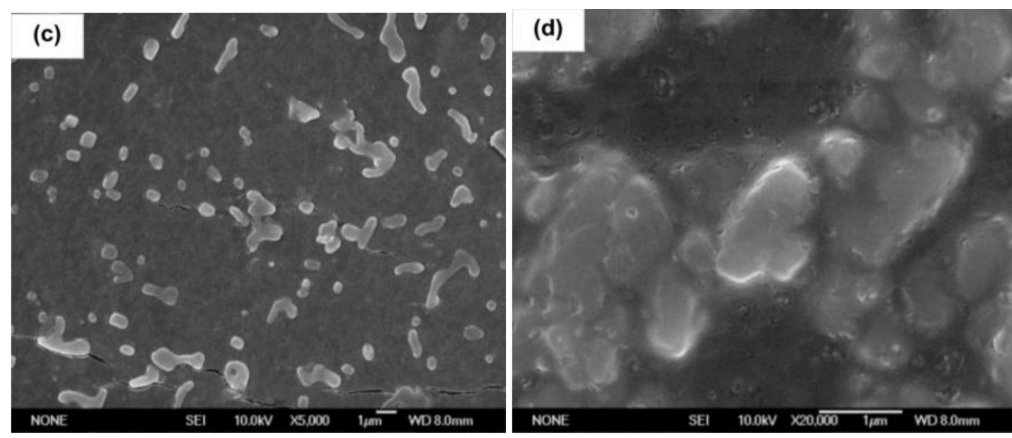

Figure 2. SEM photographs of PE film untreated and treated with D1 and analysis of atom contents on the PE film. (a) Changes in the percentage of carbon and oxygen atoms on the PE film surface after a 31-day incubation. (b) The control group without D1 bacteria (5000×). (c) The D1 on the PE surface after 31 days of cultivation under a low magnification lens $(5000 \times)$. (d) The D1 on the PE surface after 31 days of cultivation under a high magnification lens $(20000 \times)$.

\section{Results and Discussion}

\subsection{Screening of PE-Degrading Strains}

Following a 31-day cultivation, four strains were screened that could grow in the LPEM containing 5\% PE (Figure S1 and Table S1), and one strain, D1, was specifically selected because it had a better growth trend when PE was the sole carbon source. The growth of strain D1was analyzed based on the changes of $O D_{600}$, as shown in Figure 1a. When strain D1 was grown for 7 days in the LPEM (containing $5 \% \mathrm{PE}$ ), the $O D_{600}$ of the bacteria solution reached the highest value (0.24) and remained constant thereafter, whereas the $O D_{600}$ of the control (without bacteria D1) did not change over the course of 31 days. Accordingly, at the end of the cultivation, the bacterial fluid inoculated with D1 was more turbid than the control shake flask (Figure 1b). Additionally, the colonization of D1 was observed around the PE film on the APEM on day 14 of the cultivation (Figure 1c,d).

When the degradation test was cultured for 14 days, the colonization of D1 was observed around the PE film on the APEM. This results was similar to that observed by Yang et al. [21]. The observations of turbid bacterial liquid and formed bacterial colonies confirmed the utilization of carbon sources by strain D1. Additionally, steady changes of $O D_{600}$ were observed when the degradation test was cultured for 31 days. It could be inferred that D1 adapted to the nutrient conditions of the medium during the period of cultivation. Microbial adaptation to PE is a key factor for biodegradation. The present study showed that the amounts of D1 bacteria adhered to the PE film increased gradually with the extension of cultivation. Hence, D1 could potentially be effective in degrading PE. Sequence alignment of BLAST showed that the strain D1 could be Enterobacter sp. (GenBank accession no. MK934326).

The degradation of PE may be affected by the interactions between microorganisms. The commercial PE could be degraded by Bacillus licheniformis and Lysinibacillus bacterium simultaneously [22]. The mixture of Citrobacter sp. and Kosakonia sp. was capable of degrading PE and polystyrene (PS) [23]. Hence, we are also considering adding other degradation strains for degradation test.

\subsection{Determination of the Degradation Effect}

The degradation characteristics of PE are usually determined by thermogravimetric analyzer (TGA), X-ray diffraction (XRD), gas chromatograph/mass spectrometer (GC/MS), SEM, AFM, and FTIR [24]. Generally speaking, determination of weight loss is a relatively simple method used to detect the degradation of PE, however, it may not be sensitive enough under the conditions of long periods of incubation and slow biodegradation rates [25]. Therefore, no weight loss test was performed in this study. 


\subsubsection{Surface Micromorphology and Atomic Percentage}

After a 31-day incubation, surface morphology and structural changes of the PE film were observed by SEM and AFM. Figure 2 shows that the surface morphology of PE film was changed by D1, but the surface of the control remained smooth and no microorganisms were observed (Figure 2b). Figure 2c shows that D1 adhered to the surface of the PE film during the growing period. The microbial morphology was more clearly seen under a high magnification (Figure 2d). An incomplete biofilm of D1 colony formed on the surface of PE after 31 days of cultivation (Figure 2d). Analysis of elemental changes on the PE surface by SEM coupled with EDS (SEM-EDS) showed that the percentage of oxygen atoms in the D1 group was higher than that of the control group after an incubation of 31 days; the percentage of carbon atom mass was reduced by $1.98 \%$, and the percentage of oxygen atom mass was increased by $1.98 \%$ when compared with the control (Figure 2a, Tables S2 and S3). These results indicated that oxidation reaction occurred on the PE surface. Compared with the control group (Figure 3a), obvious depressions appeared on the surface of the PE film in the D1 group (Figure 3b), and the surface of the PE film was eroded by D1. In addition, cracks appeared on the microbial-treated PE film (Figure 2b), which might be related to the changes in the physical structure of the PE film during the period of biodegradation.
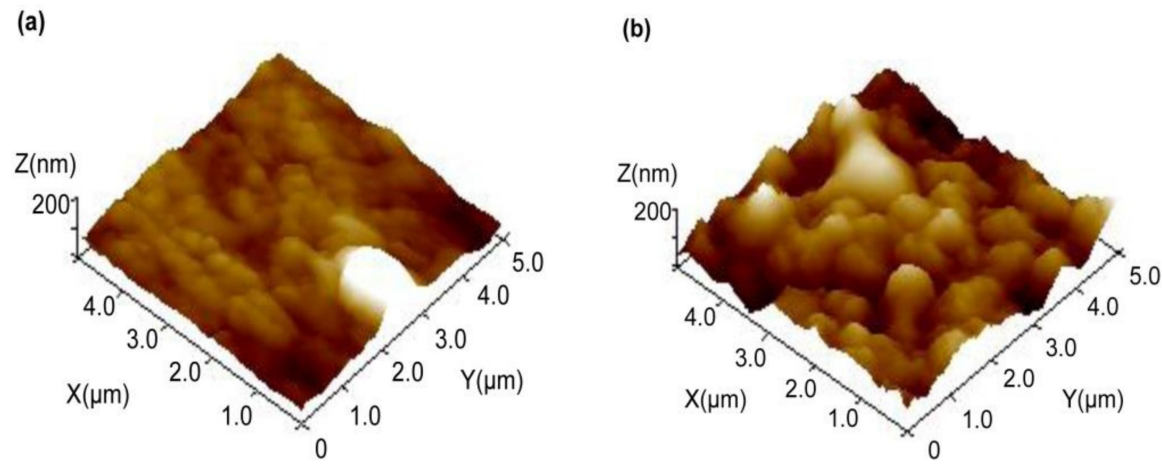

Figure 3. Physical topography of PE film untreated (a) and treated with D1 bacteria (b) by atomic force microscopy (AFM).

The results of SEM and AFM supported the findings, including the effect of D1 on the PE film from the perspective of microbial morphology, and the roughness, depressions, and cracks appeared on the PE surface. Notably, the biofilm was observed on the surface of PE film. It has been shown that microbial attachment and biofilm formation facilitated the contact of PE with microbial enzymes secreted by D1, thereby making the long carbon-carbon bond more susceptible to oxidation $[20,23,26]$. Tribedi and Sil reported the formation of biofilm by Pseudomonas sp. AKS2 strain during the degradation of polyethylene [27]. The stable AKS2 biofilm highly enhanced the hydrophobicity level of a PE film, which accelerated the degradation rate of PE [28].

It is indeed useful to see the progression of the bacterial growth and monitor the structure of PE at different times $[29,30]$. Based on the current findings, we will observe the surface morphology of PE films at different culture times to further analyze how the biofilm is formed and changed; also, we will screen and verify the degradation of PE by other strains from the gut of wax moth in future works.

\subsubsection{Changes in Chemical Structure of the PE Film Surface}

FTIR was used to analyze chemical compositions of the PE surface to help evaluate the occurrence of biodegradation. The infrared spectrum of the PE surface inoculated with D1 for 31 days showed an absorption peak at $1652 \mathrm{~cm}^{-1}$ and $1075 \mathrm{~cm}^{-1}$ corresponding to carbonyl groups $(-\mathrm{C}=\mathrm{O})$ and ether groups (-C-O-C-), respectively (Figure 4). Additionally, the absorption peaks at $730 \mathrm{~cm}^{-1}, 1435.78 \mathrm{~cm}^{-1}$, and $1450 \mathrm{~cm}^{-1}$ were observed regardless of whether the PE surface was treated with strain D1 or not. The presence of carbonyl and ether group indicated the cleavage or formation of new bonds that could 
promote the oxidation of PE. It was previously reported that the appearance of carbonyl groups on the spectrum is an indication of the biodegradation of PE [24]. It is possible that the chemical structure of PE was weakened because of the skeletal vibration during the cultivation, based on the results that both the treated group and control group had an intensive absorbance at around $730 \mathrm{~cm}^{-1}$. The appearance of bands approximately at $1450 \mathrm{~cm}^{-1}$ was due to $\mathrm{C}-\mathrm{H}$ bending vibrations in the long-chain backbone of PE.

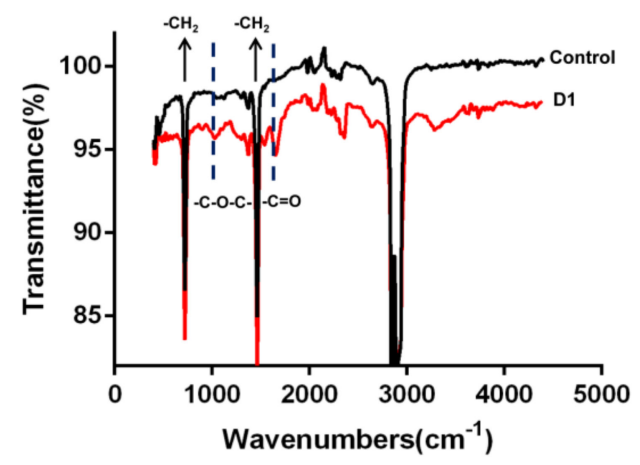

Figure 4. Distribution of carbonyl bands $\left(-\mathrm{C}=\mathrm{O}, 1652 \mathrm{~cm}^{-1}\right)$ and ether groups $\left(-\mathrm{C}-\mathrm{O}-\mathrm{C}-, 1075 \mathrm{~cm}^{-1}\right)$, observed with a FTIR microscope on the PE film treated with D1 for 31 days.

A hydrogen atom on a long carbon-carbon bond might be replaced by an oxygen atom, and functional groups such as a carbonyl group, an ester group, or an ether group formed. These functional groups contain oxygen when the $\mathrm{PE}$ is oxidized. Reports have also shown that some classical groups such as $\mathrm{C}-\mathrm{H}$ groups, $-\mathrm{C}=\mathrm{O}$ groups, $-\mathrm{C}-\mathrm{O}-\mathrm{O}$ groups, and $-\mathrm{CH}_{2}$ groups generally correspond to absorption peaks at 3000-2840 $\mathrm{cm}^{-1}, 1730-1650 \mathrm{~cm}^{-1}, 1150-1075 \mathrm{~cm}^{-1}$, and $900-735 \mathrm{~cm}^{-1}$, respectively $[17,31,32]$. Increases in ketones and double bonds provide evidence of polyethylene biodegradation, according to Balasubramanian et al. [33]. In the present study, the detection of carbonyl and ether on the PE film incubated with D1 proved that the oxidation reaction occurred. It has been shown that oxidation of PE enhanced hydrophilicity and ultimately facilitated PE biodegradation [34-36]. Some pretreatments, including photo-oxidation, thermal treatment, and acid treatment, have been shown to accelerate the oxidation and degradation of PE [37].

\subsubsection{Analysis of Water-Soluble Products}

The water-soluble products of the solution resulting from the 31 days of cultivation of the PE film were analyzed by LC-MS. The eluted compounds contained almost all C, H, and O elements. Significant differences were found in the abundance, suggesting the compounds were different between the two groups (Figure 5a). The compounds including alcohols, esters, and acids were significantly increased in the D1-treated group compared with the control group (Table S4). The content of ethyldodecanoate and 6-methyl-5-hepten-2-ol in the D1 group was 4 times higher than the control group (Figure 5b). Several compounds such as monobenzyl phthalate and N-Acetylglutamic acid were detected and considered as newly formed compounds in the D1 group, while they were not detected in the control group (Figure 5b).

Alcohols, alkanes, hydrocarbon, esters, and acids are detected by LC-MS, which reflects the metabolism of bacteria during the PE biodegradation [38]. Monobenzyl phthalate is the main metabolite of butyl benzyl phthalate (BBP). We speculated that the production of monobenzyl phthalate was caused by some oxidoreductases secreted by the strain Enterobacter sp. and the specific oxidation mechanism was further studied. The current study showed that the long-chain carbon-carbon bond of PE was oxidized during the period of cultivation, given the results showing that alcohols, esters, and acids were significantly increased. Although the control and D1-treated group shared some compounds, their contents were significantly different. The differences were attributed to the utilization of nitrogen and carbon sources by microorganisms in the medium and the photooxidation of PE film occurred during the cultivation $[21,25,38]$. Furthermore, some other compounds such as N-acetylglutamic acid 
might be the secondary metabolic products secreted by the strain D1 when utilizing PE to grow. These differences in the compounds could help demonstrate that PE was degraded by strain D1 [21].
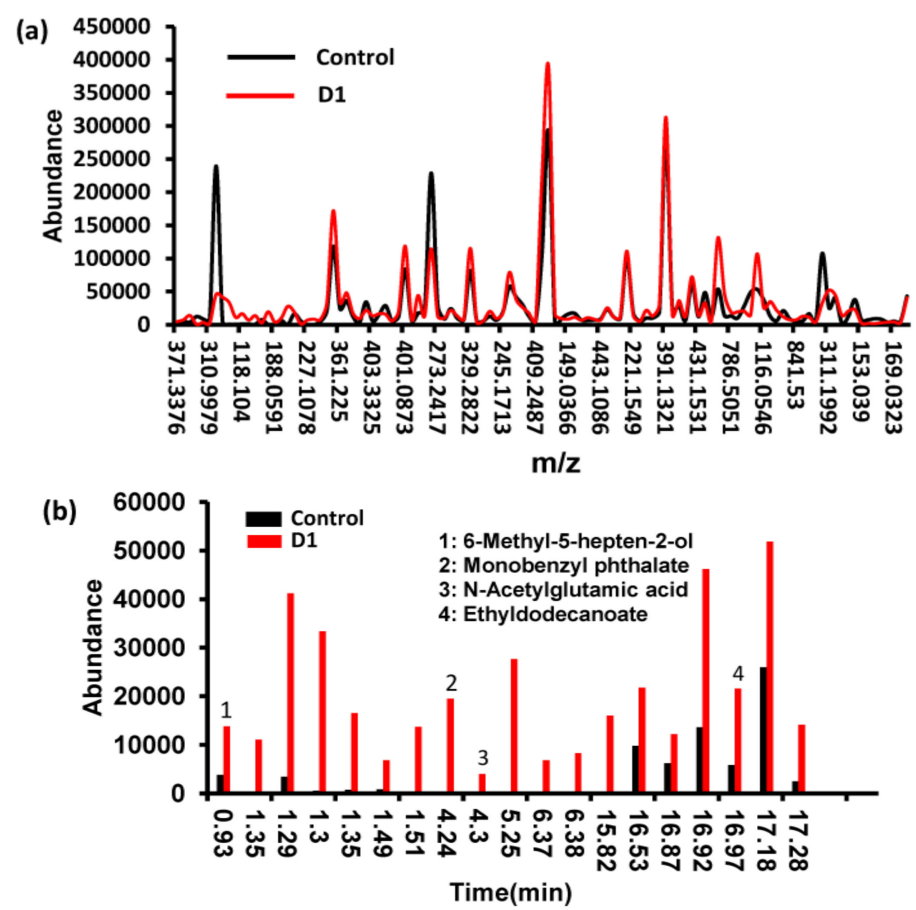

Figure 5. Detection of water-soluble products by LC-MS at the end of 31 days of cultivation. (a) Comparison of the abundance of compounds eluted at the same $\mathrm{M} / \mathrm{Z}$ between the control group and the D1-treated group. (b) Increased abundances of acids, esters, and alcohols were observed in the D1-treated group compared with the control group.

Currently, we have initially detected the production of alcohols, alkanes, hydrocarbon, esters, and acids. The biodegradation mechanism of PE is complex and involves the participation of various oxidoreductases. It has been reported that the biodegradation of PE by microbial enzymes is much more efficient relative to microorganisms [39]. Studies have shown that extracellular enzymes were capable of attacking and modifying PE films and that the laccase-mediator system could decrease the $\mathrm{Mw}$ of polyethylene from 242,000 to 28,300 for 3 days $[40,41]$. However, the degrading enzymes that have been studied usually have poor stability, and the mechanism of biodegradation of PE remains limited in the literature. Therefore, it would be of great interest to identify enzymes from microorganisms that can efficiently degrade $\mathrm{PE}$, and investigate possible mechanisms underlying the enzymatic degradation.

\section{Conclusions and Future Perspectives}

In this study, the strain Enterobacter sp. D1 was screened from the gut homogenate of the wax moth by using PE as the sole carbon source. Further analysis confirmed that PE could be degraded by strain D1. As a carbon source, PE materials are not easily utilized by microorganisms compared to glucose and beef extract, due to their structural particularities (hydrophobicity, high molecular weight, etc.). The current research shows that the desirable degradation effect of PE was not achieved at the laboratory level regardless of microbes or degrading enzymes. This is a challenge for us to continue to study the degradation effect of Enterobacter sp. on PE.

In our future studies, we are planning to use the following methods to potentially improve the degradation rate: (1) addition of other PE degradation strains to the culture medium for possible synergistic effects; (2) addition of surfactants (such as Tween-80, mineral oil, or paraffin oil) to the culture medium to potentially improve the hydrophilicity of the PE surface and accelerate the formation 
of biofilm; (3) pretreatment (ultraviolet irradiation, acid treatment, etc.) of the PE film; and (4) mutation and domestication of the degrading strains.

Supplementary Materials: The following are available online at http://www.mdpi.com/1660-4601/16/11/1941/s1: Figure S1: The changes of $O D_{600}$ of the four strains during the 31-day cultivation. The four strains were screened from the gut homogenate of the wax moth that could grow in the LPEM containing $5 \%$ PE, Table S1: The estimated $O D_{600}$ of every sample during the 31-day cultivation, Table S2: Statistical summary of the atom $\mathrm{C}$ and $\mathrm{O}$ on the surface of PE film, Table S3: Independent samples test for the atomic percentage of every sample, Table S4: Detection of the significantly increased compounds from the bacterial solution of the D1 group compared with the control group by LC-MS at the end of the 31-day cultivation.

Author Contributions: The study was conceived and designed by J.W. and Y.Z. The manuscript was performed and written by L.R. The data was analyzed by L.R., Y.Z., J.W., and W.Z. The raising of the wax moths and the extracting of the intestinal contents were performed by L.M. and Z.Z. Testing of SEM, AFM, and LC-MS was done by F.G. and J.T. Detection of LC-MS was done by B.W.

Funding: This work was supported by the Central Public-interest Scientific Institution Basal Research Fund (Y2018LM02, Y2019XK19), the Xinjiang Key Research and Development Program of China (2018B01006-1), and the National Major Project of "Water Pollution Control and Governance" (2017ZX07202-002-06) in China.

Conflicts of Interest: The authors declare no conflict of interest.

\section{References}

1. Krueger, M.C.; Harms, H.; Schlosser, D. Prospects for microbiological solutions to environmental pollution with plastics. Appl. Environ. Microb. 2015, 99, 8857-8874. [CrossRef]

2. Acampora, H.; Berrow, S.; Newton, S.; O'Connor, I. Presence of plastic litter in pellets from Great Cormorant (Phalacrocorax carbo) in Ireland. Mar. Pollut. Bull. 2017, 117, 512-514. [CrossRef] [PubMed]

3. Rillig, M.C.; Bonkowski, M. Microplastic and soil protists: A call for research. Environ. Pollut. 2018, 241, 1128-1131. [CrossRef] [PubMed]

4. Li, J.; Yang, D.; Li, L.; Jabeen, K.; Shi, H. Microplastics in commercial bivalves from China. Environ. Pollut. 2015, 207, 190-195. [CrossRef] [PubMed]

5. Jabeen, K.; Su, L.; Li, J.; Yang, D.; Tong, C.; Mu, J.; Shi, H. Microplastics and mesoplastics in fish from coastal and fresh waters of China. Environ. Pollut. 2017, 221, 141-149. [CrossRef] [PubMed]

6. Song, J.J.; Yoon, S.C.; Yu, S.M.; Lenz, R.W. Differential scanning calorimetric study of poly (3-hydroxyoctanoate) inclusions in bacterial cells. Int. J. Biol. Macromol. 1998, 23, 165-173. [CrossRef]

7. Ioakeimidis, C.; Fotopoulou, K.N.; Karapanagioti, H.K.; Geraga, M.; Zeri, C.; Papathanassiou, E.; Galgani, F.; Papatheodorou, G. The degradation potential of PET bottles in the marine environment: An ATR-FTIR based approach. Sci. Rep. 2016, 6, 23501. [CrossRef] [PubMed]

8. Shimao, M. Biodegradation of plastics. Curr. Opin. Biotechnol. 2001, 12, 242-247. [CrossRef]

9. Shah, A.A.; Hasan, F.; Akhter, J.I.; Hameed, A.; Ahmed, S. Degradation of polyurethane by novel bacterial consortium isolated from soil. Ann. Microbiol. 2008, 58, 381-386. [CrossRef]

10. Singh, B.; Sharma, N. Mechanistic implications of plastic degradation. Polym. Degrad. Stab. 2008, 93, 561-584. [CrossRef]

11. Yang, J.; Yang, Y.; Wu, W.M.; Zhao, J.; Jiang, L. Evidence of polyethylene biodegradation by bacterial strains from the guts of plastic-eating waxworms. Environ. Sci. Technol. 2014, 48, 13776-13784. [CrossRef] [PubMed]

12. Plastics Europe. An Analysis of European Plastics Production, Demand and Waste Data; Plastics Europe: Brussels, Belgium, 2018; pp. 46-49. Available online: http://www.epro-plasticsrecycling.org (accessed on 15 February 2019).

13. Restrepo-Flórez, J.M.; Bassi, A.; Thompson, M.R. Microbial degradation and deterioration of polyethylene-A review. Int. Biodeterior. Biodegrad. 2014, 88, 83-90. [CrossRef]

14. Pegram, J.E.; Andrady, A.L. Outdoor weathering of selected polymeric materials under marine exposure conditions. Polym. Degrad. Stab. 1989, 26, 333-345. [CrossRef]

15. Jones, P.H.; Prasad, D.; Heskins, M.; Morgan, M.H.; Guillet, J.E. Biodegradability of photodegraded polymers I. Development of experimental procedures. Environ. Sci. Technol. 1974, 8, 919-923. [CrossRef]

16. Watanabe, M.; Kawai, F.; Shibata, M.; Yokoyama, S.; Sudate, Y. Computational method for analysis of polyethylene biodegradation. J. Comput. Appl. Math. 2003, 161, 133-144. [CrossRef]

17. Yamada-Onodera, K.; Mukumoto, H.; Katsuyaya, Y.; Saiganji, A.; Tani, Y. Degradation of polyethylene by a fungus, Penicillium simplicissimum YK. Polym. Degrad. Stab. 2000, 72, 323-327. [CrossRef] 
18. Bombelli, P.; Howe, C.J.; Bertocchini, F. Polyethylene bio-degradation by caterpillars of the wax moth Galleria mellonella. Curr. Biol. 2017, 27, 292-293. [CrossRef] [PubMed]

19. SAI Global. Standard Practice for Determining Resistance of Plastics to Bacteria; ASTM G 22-76; SAI Global: Adelaide, Australia, 1996.

20. Sivan, A.; Szanto, M.; Pavlov, V. Biofilm development of the polyethylene-degrading bacterium Rhodococcus ruber. Appl. Microbiol. Biotechnol. 2006, 72, 346-352. [CrossRef] [PubMed]

21. Dang, T.C.H.; Nguyen, D.T.; Thai, H.; Nguyen, T.C.; Hien Tran, T.T.; Le, V.H.; Nguyen, V.H.; Tran, X.B.; Thao Pham, T.P.; Nguyen, T.G.; et al. Plastic degradation by thermophilic Bacillus sp. BCBT21 isolated from composting agricultural residual in Vietnam. Adv. Nat. Sci. Nanosci. Nanotechnol. 2018, 9, 015014. [CrossRef]

22. Mukherjeea, S.; Chaudhurib, U.R.; Kundua, P.P. Bio-degradation of polyethylene waste by simultaneous use of two bacteria: Bacillus licheniformis for production of Bio-surfactant and Lysinibacillus fusiformis for Biodegradation. RSC Adv. 2016, 6, 2982-2992. [CrossRef]

23. Brandon, A.M.; Gao, S.H.; Tian, R.; Ning, D.; Yang, S.S.; Zhou, J.; Wu, W.M.; Criddle, C.S. Biodegradation of polyethylene and plastic mixtures in mealworms (larvae of tenebrio molitor) and effects on the gut microbiome. Environ. Sci. Technol. 2018, 52, 6526-6533. [CrossRef]

24. Mehmood, C.T.; Qazi, I.A.; Hashmi, I.; Bhargava, S.; Deepa, S. Biodegradation of low density polyethylene (LDPE) modified with dye sensitized titania and starch blend using Stenotrophomonas pavanii. Int. Biodeterior. Biodegrad. 2016, 113, 276-286. [CrossRef]

25. Kyaw, B.M.; Champakalakshmi, R.; Sakharkar, M.K.; Lim, C.S.; Sakharkar, K.R. Biodegradation of low density polythene (LDPE) by Pseudomonas species. Indian J. Microbiol. 2012, 52, 411-419. [CrossRef] [PubMed]

26. Skariyachan, S.; Patil, A.A.; Shankar, A.; Manjunath, M.; Bachappanavar, N.; Kiran, S. Enhanced polymer degradation of polyethylene and polypropylene by novel thermophilic consortia of Brevibacillus sps. and Aneurinibacillus sp. screened from waste management landfills and sewage treatment plants. Polym. Degrad. Stab. 2018, 149, 52-68. [CrossRef]

27. Tribedi, P.; Sil, A.K. Low-density polyethylene degradation by Pseudomonas sp. AKS2 biofilm. Environ. Sci. Pollut. Res. 2013, 20, 4146-4153. [CrossRef] [PubMed]

28. Tribedi, P.; Gupta, A.D.; Sil, A.K. Adaptation of Pseudomonas sp. AKS2 in biofilm on low-density polyethylene surface: An effective strategy for efficient survival and polymer degradation. Bioresour. Bioprocess. 2015, 2, 14. [CrossRef]

29. Da Costa, J.P.; Nunes, A.R.; Santos, P.S.M.; Girao, A.V.; Duarte, A.C.; Rocha-Santos, T. Degradation of polyethylene microplastics in seawater: Insights into the environmental degradation of polymers. J. Environ. Sci. Health Part A Toxic Hazard. Subst. Environ. Eng. 2018, 53, 866-875. [CrossRef]

30. Lwanga, E.H.; Thapa, B.; Yang, X.; Gertsen, H.; Salanki, T.; Geissen, V.; Garbeva, P. Decay of low-density polyethylene by bacteria extracted from earthworm's guts: A potential for soil restoration. Sci. Total Environ. 2018, 624, 753-757. [CrossRef] [PubMed]

31. Kowalczyk, A.; Chyc, M.; Ryszka, P.; Latowski, D. Achromobacter xylosoxidans as a new microorganism strain colonizing high-density polyethylene as a key step to its biodegradation. Environ. Sci. Pollut. Res. Int. 2016, 23, 11349-11356. [CrossRef] [PubMed]

32. Yoon, M.G.; Jeon, H.J.; Kim, M.N. Biodegradation of polyethylene by a soil bacterium and AlkB cloned recombinant cell. J. Bioremed. Biodegrad. 2012, 3, 145. [CrossRef]

33. Balasubramanian, V.; Natarajan, K.; Hemambika, B.; Ramesh, N.; Sumathi, C.S.; Kottaimuthu, R.; Kannan, V.R. High-density polyethylene (HDPE)-degrading potential bacteria from marine ecosystem of Gulf of Mannar, India. Lett. Appl. Microbiol. 2010, 51, 205-211. [CrossRef] [PubMed]

34. Agamuthu, P.; Faizura, P.N. Biodegradability of degradable plastic waste. Waste Manag. Res. 2005, 23, 95-100. [CrossRef] [PubMed]

35. Cai, L.; Wang, J.; Peng, J.; Wu, Z.; Tan, X. Observation of the degradation of three types of plastic pellets exposed to UV irradiation in three different environments. Sci. Total Environ. 2018, 79, 740-747. [CrossRef]

36. Montazer, Z.; Habibi-Najafi, M.B.; Mohebbi, M.; Oromiehei, A. Microbial degradation of UV-pretreated low-density polyethylene films by novel polyethylene-degrading bacteria isolated from plastic-dump soil. J. Polym. Environ. 2018, 26, 3613-3625. [CrossRef]

37. Balasubramanian, V.; Natarajan, K.; Rajeshkannan, V.; Perumal, P. Enhancement of in vitro high-density polyethylene (HDPE) degradation by physical, chemical, and biological treatments. Environ. Sci. Pollut. Res. Int. 2014, 21, 12549-12562. [CrossRef] [PubMed] 
38. Shahnawaz, M.; Sangale, M.K.; Ade, A.B. Bacteria-based polythene degradation products: GC-MS analysis and toxicity testing. Environ. Sci. Pollut. Res. Int. 2016, 23, 10733-10741. [CrossRef] [PubMed]

39. Devi, R.; Kannan, V.; Natarajan, K.; Nivas, D.; Kannan, K.; Chandru, S.; Antony, A. The role of microbes in plastic degradation. In Environmental Waste Management; CRC Press: Boca Raton, FL, USA, 2015; pp. 341-370.

40. Pometto, A.L., III; Lee, B.; Jonhson, K.E. Production of an extracellular polyethylene-degrading enzyme(s) by Streptomyces species. Appl. Environ. Microbiol. 1991, 58, 731-733. [CrossRef]

41. Fujisawa, M.; Hirai, H.; Nishida, T. Degradation of polyethylene and Nylon-66 by the Laccase-mediator system. J. Polym. Environ. 2002, 9, 103-108. [CrossRef]

(C) 2019 by the authors. Licensee MDPI, Basel, Switzerland. This article is an open access article distributed under the terms and conditions of the Creative Commons Attribution (CC BY) license (http://creativecommons.org/licenses/by/4.0/). 